NBER WORKING PAPER SERIES

\title{
PRODUCT DIFFERENTIATION AND FILM PROGRAMMING CHOICE: DO FIRST-RUN MOVIE THEATRES SHOW THE SAME FILMS?
}

\author{
Darlene C. Chisholm \\ Margaret S. McMillan \\ George Norman \\ Working Paper 12646 \\ http://www.nber.org/papers/w12646
}

\author{
NATIONAL BUREAU OF ECONOMIC RESEARCH \\ 1050 Massachusetts Avenue \\ Cambridge, MA 02138 \\ October 2006
}

We are grateful to the DeSantis Center for Motion Picture Industry Studies of Florida Atlantic University College of Business and Economics for providing a grant to fund this research and to Synergy Retail for compiling the data set used in this paper. For valuable comments and suggestions, we thank Bart Addis, Thomas Downes, F. Andrew Hanssen, Sanjiv Jaggia, Zaur Rzakhanov, Alfonso Sanchez-Penalver, Richard Startz, Andrew Sweeting, Chih Ming Tan, Charles Weinberg, Jeffrey Zabel, and seminar participants at the DeSantis Center Summit Workshop, the International Industrial Organization Conference, and the CORE Universite Catholique de Louvain Conference on Hotelling's Legacy and its Future. We are grateful to Vicky Huang, Anna Kumysh, and Vidisha Vachharajani for their careful research assistance and to Sorin Codreanu for his data-management programming assistance. The views expressed herein are those of the author(s) and do not necessarily reflect the views of the National Bureau of Economic Research.

(C) 2006 by Darlene C. Chisholm, Margaret S. McMillan, and George Norman. All rights reserved. Short sections of text, not to exceed two paragraphs, may be quoted without explicit permission provided that full credit, including () notice, is given to the source. 
Product Differentiation and Film Programming Choice: Do First-Run Movie Theatres Show the Same Films?

Darlene C. Chisholm, Margaret S. McMillan, and George Norman

NBER Working Paper No. 12646

October 2006

JEL No. C33,L11,L82

\begin{abstract}
We present an empirical analysis of product differentiation using a new dynamic panel data set on film programming choice in a major U.S. metropolitan motion-pictures exhibition market. Using these data, we compute two measures of film programming choice which allow us to investigate the determinants of strategic product differentiation in a multi-characteristics space. Our evidence is consistent with the idea that the degree of product differentiation between theatre pairs reflects a balance between strategic concerns and contractual constraints. Similarity in one dimension is offset by differentiation in others. Finally, we find that ownership matters: theatres under common ownership make more similar programming choices than theatres with different owners.
\end{abstract}

Darlene C. Chisholm

Suffolk University

Department of Economics

George Norman

8 Ashburton Place

Tufts University

Boston, MA 02108

Department of Economics

darlene.chisholm@suffolk.edu

Medford MA 02155

Margaret S. McMillan

george.norman@tufts.edu

Tufts University

8 Exmoor Road

Newton Centre, MA 02459

and NBER

Margaret.mcmillan@tufts.edu 


\section{Introduction}

The seminal analysis by Hotelling (1929) on "Stability in Competition” has sparked a large and growing theoretical literature concerned with the following deceptively simple questions. Should we expect to find, as Hotelling claimed, that firms offering horizontally differentiated products choose product designs with minimum differentiation? Or, should we expect to find, as d'Aspremont et al. (1979) claim in their critique of Hotelling, that these same firms seek maximal differentiation in their product designs in order to soften competition?

The simple but frustrating answer to these theoretical questions is that "it depends". Specifically, it depends upon the particular modeling assumptions that we make. Borenstein and Netz (1999) aptly characterize the reason for the theoretical ambiguity. ${ }^{1}$ Non-cooperative firms balance two forces when making their location, or, more generally, product-design choices: an “attraction” force that draws a firm closer to its rivals in order to steal business from them and a “repulsion” force that induces firms to separate in order to soften competition. ${ }^{2}$ There is no $a$ priori reason to believe that one of these forces always dominates the other.

When theory is inconclusive, we must turn to empirical or experimental investigation to shed light on the interplay between these attraction and repulsion forces. Unfortunately, very few such investigations are available. Significant exceptions include Borenstein and Netz (1999) and Netz and Taylor (2002) who provide empirical evidence on this tension as it affects airline departure scheduling and the location of gas stations, respectively. Davis (2006) develops an empirical model of consumer choice in the U.S. motion-pictures industry, using spatial and

\footnotetext{
${ }^{1}$ In addition, they provide an extensive review of the current literature on product differentiation. See also Chisholm and Norman (2004).

2 Tirole (1988) refers to a similar tension between differentiation to soften price competition and agglomeration to "be where the demand is" (1988, p. 286).
} 
demographic market characteristics. ${ }^{3}$ Seim (2005) develops a model of entry, allowing product price to be endogenously determined, using data from the retail video rental market, focusing on spatial differentiation. Sweeting (2006) extends the concept of spatial differentiation to similarities and differences in radio programming choices, and Berry and Waldfogel (2001) provide evidence of increased product variety with increasing market concentration in the same industry.

Our paper adds to this literature by examining a dynamic type of product differentiation: the weekly film programming choices made by first-run movie theatres within the well-defined geographic area of the Boston metropolitan market. We can think of a first-run movie theatre as offering a product with multiple characteristics: besides the location of the theatre there is also the number of different films being shown and the number of screenings of these films. On this basis, movie theatre $i$ is less differentiated from movie theatre $j$ in a particular period the more movies, or screenings, they have in common in that period.

Our analysis allows us to provide empirical evidence with respect to several important questions relating to product design and product re-design.

First, do first-run movie theatres that are in more direct competition with each other on one dimension, such as the locations of the theatres, adopt product designs - film programming selections - that are more, or less, similar? Unfortunately, theory is largely silent on product design choices when products have multiple characteristics. Irmen and Thisse (1998) provide one of the few such analyses. They develop a model with quadratic utility loss that might be

\footnotetext{
${ }^{3}$ Corts (2001) empirically examines the related issue of the impact vertical market structure has on U.S. motionpicture releases. Mazzeo (2002a and 2002b) finds evidence of product differentiation as a mechanism to soften competition in the motel industry. There is also preliminary work by Einav (2003), which treats the timing of releases of new movies as an important endogenous product characteristic.
} 
expected to generate maximal differentiation, but show that if there is a "dominant" characteristic, then firms will maximally differentiate on this characteristic and minimally differentiate on the others.

Our empirical context is, of course, much more complex than that envisaged by Irmen and Thisse. Complicating factors include: heterogeneous consumers; product characteristics that are not easily classified as being dominant or dominated; and the ability to change product design (movie mix) over time at relatively low cost. Nevertheless, it seems reasonable to suggest that an empirical implication of the Irmen and Thisse analysis is that if movie theatres are "close" to each other in one set of characteristics, whether by choice or as a result of an exogenous factor, they will seek to differentiate themselves on other characteristics. Tirole (op. cit.) and much of the marketing literature ${ }^{4}$ offer similar predictions: simply put, it pays to be different, but not too different.

Second, to what extent does ownership matter in product design? A familiar and not surprising result from theory is that multi-product firms typically make different location or product design choices from single-product non-cooperative oligopolists. ${ }^{5}$ In our specific context, we should expect that a multi-outlet firm, such as a theatre chain, makes different design decisions from those of a single-outlet firm. Full coordination of product-design choice by a particular multi-outlet firm is unlikely to be feasible, however, since this firm is also in competition with other single- and multi-outlet firms.

A novel feature of our data is that we track weekly movie selection for each first-run theatre in our sample for a period of 52 weeks. This allows us to examine some of the dynamics

\footnotetext{
${ }^{4}$ See, for example, Kerin et al. (2006).

${ }^{5}$ See, for example, Chisholm and Norman (2004), Norman and Pepall (2000), Pal and Sarkar (2002).
} 
of product differentiation. In particular, the specific contractual system within which the movie theatres operate has a significant impact on the exhibitors' choice of which movies to show in particular weeks. The major studios typically release what they hope to be "blockbuster" movies close to important holidays and negotiate with the distributors and exhibitors to secure extensive coordinated release of these movies: the release of the final film in the "Lord of the Rings" trilogy is just one case in point. As a result, we would expect to find greater similarity in movie selection nearer to major holidays but rather less similarity in weeks "far" from the major holidays.

However, we should be careful not to push this interpretation of the "holiday effect" too far. Theatre managers can at least partially offset similarity in programming choice forced by exhibitors at major holidays through their choices of the other films that they show in those weeks. Moreover, the conjectured "holiday effect" can be attributed to another important factor. There is strong evidence of significant seasonality in movie attendance (Einav 2006), with audience size reaching a peak at the major holidays and declining away from the holidays. The theoretical literature is largely silent on the relationship between market size and product differentiation. In related analysis of product line rivalry, however, preliminary results (Chisholm and Norman, 2006a) indicate that as market size increases we should expect to find more overlap in product lines. In our specific application, we should find a positive relationship between similarity in programming choice and each theatre owner's prior on expected aggregate movie attendance for a particular week.

Our main findings can be summarized as follows. First, movie theatres that are located geographically more closely to each other make film programming choices that are less similar. 
Second, similarity is high close to major holidays but then declines with "distance” from such holidays. Third, ownership matters in the sense that theatre pairs under common ownership tend to be more similar in their film programming choices than do theatre pairs that have different owners. The first two results are consistent with our theoretical expectations. The third implies that the advantages of centralized contracting by theatres' owners with movie distributors, and the importance of the center's reading of the market, affect programming choice more than local strategic considerations.

In the next section we develop our measures of similarity in product design. Section III proposes a number of empirically testable determinants of similarity; Section IV describes the data, their sources and institutional background; Section V presents our empirical analysis; and Section VI provides concluding remarks.

\section{Measuring Product Differentiation in a Strategic Market Setting}

The dependent variable throughout our analysis is the degree of product similarity, measured weekly, between pairs of first-run movie theatres. We consider two such measures. The first, $S A_{i j t}$, motivated by Jaffe (1986), measures the angle between two vectors whose elements reflect each theatre's product attributes (movies being shown) between theatre $i$ and theatre $j$ in a particular week $t$. This is an inverse measure of similarity in that the greater the angle, the lower is the similarity. ${ }^{6}$ The second, $S M_{i j t}$, measures the percentage of movie matches between theatre $i$ and theatre $j$, in a particular week $t$, relative to the total number of possible matches, with an appropriate normalization described below, and so provides a direct measure of similarity.

\footnotetext{
${ }^{6}$ Sweeting (2006) adopts a similar measure to capture differentiation in radio programming.
} 
A complication in measuring similarity in our specific context is that popular films may be shown on multiple screens in a given week. As a result, our measure of similarity will differ depending upon whether we measure similarity in screenings or similarity in movies. Our econometric analysis considers both screening and movie measures of similarity.

For both the angular and the matching measures of similarity, we consider a well-defined geographic market, in our case the Boston metropolitan area. For each week $t$ we begin by counting the total number of films, $N_{t}$, playing in the first-run movie theatres across the entire market on a particular day: given our data sources, we chose the Friday of each week. We define the angular measure, $S A_{i j t}$, based on screenings, as follows. The attributes vector $A_{i t}$ for theatre $i$ in week $t$ has length $N_{t}$, where the $n$th element $a_{n i t}$ corresponds to the $n$th film, with the films ordered alphabetically. Suppose theatre $i$ has five screens, each of which can show four films on a typical Friday and thus possesses a total "showings capacity" of 20 time slots. Suppose further that in week $t$ theatre $i$ is showing four films, one of which is presented on two screens, out of a total of ten films that are being shown across the entire market that week. The elements of the attributes vector corresponding to the four films playing at theatre $i$ are the percentages of screen capacity devoted to each film. In the present example, three of the $a_{n i t}$ cells equal 0.20 ; the fourth cell, corresponding to the film showing on two screens, equals 0.40 . The remaining six cells of the attributes vector equal zero to reflect the absence of a current film from theatre $i$ 's offerings in that week. The attributes vector $A_{j t}$ for theatre $j$ is constructed analogously.

The angular measure of the similarity between the two theatres' film offerings based on screenings is the angle between vector $A_{i t}$ and vector $A_{j t}$ : 


$$
S A_{i j t}=\arccos \left(\frac{A_{i t} \cdot A_{j t}}{\left\|A_{i t}\right\|\left\|A_{j t}\right\|}\right)
$$

converted to degrees. Thus if the two theatres have an identical set of films, with an identical distribution across screens, the angle between the vectors will be zero. The angle between the vectors increases, and approaches 90 degrees, the more dissimilar or differentiated the theatres are relative to one another.

An alternative angular measure we consider focuses on a simple comparison of films showing at theatres $i$ and $j$. Again, in week $t$ we begin with a vector of length $N_{t}$ as defined above. If a film is playing at theatre $i$, the element in the vector corresponding to that film equals one; it equals zero otherwise. If both theatre $i$ and theatre $j$ are showing the same set of films, even if the capacity distribution differs, the angle between the movie-count attributes vectors will be zero, implying "identical" products in a qualitative, but not proportionate, sense. As the two theatres’ offerings diverge, this angular measure again approaches 90 degrees.

A particular advantage of the angular measure of similarity, whether based on screenings or films, is that the "measure of proximity is purely directional i.e. it is not directly affected by the length of the (A) vectors.” (Jaffe, 1986, p. 986, fn 5) In our specific context, the angular measure of similarity is unaffected by variation in the number of films shown in different weeks.

A limitation of the angular measure, however, is that it is sensitive to differences in the number of screens between theatres $i$ and $j$ : the greater is this difference, the greater $S A_{i j t}$ is likely to be. In contrast to the matching measure (see below), no simple normalization for the impact of differences in numbers of screens suggests itself. As a result, in the empirical implementation we include an independent variable that is designed to capture this effect. 
The second similarity measure we consider is derived from the percentage of matches between two theatres and thus quite naturally ranges between zero and one as two theatres move from perfectly dissimilar, or highly differentiated, to perfectly identical, or homogeneous. Once again, we must take into account two complicating factors. First, the number of screens at a particular theatre affects the movie mix that the theatre can offer. Second, there is the possibility that a particular film might be shown on multiple screens in one theatre but not in another.

This suggests the following approach for any pair of theatres $i$ and $j$ in each week $t$. For each film playing at theatre $i$, determine if that film is also playing at theatre $j$ in that week. If so, and if the film is playing three times at theatre $i$ and four times at theatre $j$, the number-ofscreenings matches for this film is three. Add this to the other number-of-screenings matches for all other common films across both theatres to derive the total number of screenings in common, $S_{c t}$. This information is used to generate a similarity metric:

$$
S_{i j t}=\frac{S_{c t}^{2}}{\bar{S}_{i} \cdot \bar{S}_{j}}
$$

where $\bar{S}_{h}$ is the number of screenings that is possible at movie theatre $h=i, j$.

An obvious limitation of $S_{i j t}$ is that, while it is distributed on the interval [0,1], it is concatenated in this interval if $\bar{S}_{i} \neq \bar{S}_{j}$. In other words, as with the angular measure the matching measure in (2) is affected by differences in the number of screens between theatre pairs. In this case, however, a simple correction for this potential bias is available. We normalize $S_{i j t}$ by the maximum degree of similarity $\bar{S}_{i j}=\left(\left(\min \left(\bar{S}_{i}, \bar{S}_{j}\right)\right)^{2} / \bar{S}_{i} \cdot \bar{S}_{j}\right)$ and scale it by 100 to give a percentage match, leading to the matching similarity measure: 


$$
S M_{i j t}=100\left(\frac{S_{c t}}{\min \left(\bar{S}_{i}, \bar{S}_{j}\right)}\right)^{2}
$$

The normalized matching similarity index (3) can be thought of as a count measure, reflecting the number of "successes" (or matches) the two products mutually possess, relative to the maximum potential for success (or matches). Note also that, as with the angular measure, $N_{t}$ does not directly affect this measure of similarity.

\section{Determinants of Product Similarity}

We now turn to the specific strategic and institutional factors that might be expected to influence the degree of similarity in film programming choice between two theatres. In doing so, we distinguish between time-invariant effects that are likely to affect similarity in programming across weeks and time-variant effects that are likely to affect the dynamics of film programming choice.

Given the nature of our data and the theory discussed in the introduction, there are three obvious time-invariant effects that we expect will influence the degree of similarity in movie selection for each theatre pair. First, theatres that are located close to each other are likely to be in competition much more directly than those that are geographically separated. In order to test for this effect we construct DISTANCE $E_{i j}$, the distance in miles between theatre $i$ and theatre $j$, derived from GPS data for each theatre. We expect that theatres more closely located to each other in one characteristic, in this case geographic location, will seek to differentiate themselves in other characteristics (movie offerings) in order to soften competition for customers. Thus we expect the angular similarity index to decrease, and the proportionate similarity index to 
increase, with DISTANCE. ${ }^{7}$ To test the robustness of our distance measure, we also consider travel time between theatre $i$ and theatre $j$ as an alternative measure, using estimates from MapQuest.com based on each theatre’s street address.

Second, we expect to find that "ownership matters" in film programming choice, but in this case precisely how is not clear a priori. To capture the different incentives that might arise when two theatres are owned by the same company, we create the dummy variable $S A M E O W N E R_{i j}$, which equals one if theatre $i$ and theatre $j$ are owned by the same company, and zero otherwise. If companies negotiate better contracting terms with distributors when movies are acquired in bulk, or if programming decisions are centralized and affected by the "center's" reading of the market, we would expect SAMEOWNER to increase programming similarity. By contrast, if programming decisions are centralized and dominated by the desire to avoid direct competition between theatres under common ownership, we would expect SAMEOWNER to decrease similarity. Finally, if individual theatres behave autonomously, with inter-theatre competitive forces dominating programming choice, and with few economies from large-scale distribution contracts, then SAMEOWNER should have little or no effect.

Third, we expect that programming choice will be affected at least in part by demographics, to the extent that movie-going choices differ by the precise characteristics of the movie-going population "close to," and thus within, the natural catchment area of a particular movie theatre. We test for the importance of differences in a number of demographic variables,

\footnotetext{
${ }^{7}$ A movie distributor might decide that only one theatre, within close proximity to another, is allowed to show a particular film based on a clearance zone. While data are not available on the specific clearance terms of the films in our data set, the existence of such contracts only serve to enhance to predicted impact of DISTANCE on similarity.
} 
including age, income, population, and households, each measured within three-, five-, and tenmile radii of each of the theatres in a given $i j$ pair.

We noted in the introduction that film programming choice across theatres is likely to be affected by proximity to major holidays for two reasons. First, since our focus is on first-run theatres in a major metropolitan area, we would expect similarity in programming choice to be greatest in the vicinity of major holidays when many of the theatre owners are contractually committed to allocate multiple screens to "holiday" films, whose release dates are announced several months in advance. Second, we expect to find a relationship between seasonality in demand, as documented in Einav (2006), and programming similarity. Specifically, we expect to find greater (lesser) similarity in programming choice when expected demand is high (low).

We test for the seasonality, or market size, effect in three ways. First, we use HOLIDAYDISTANCE $E_{t}$ defined as the number of weeks the current week is away from the nearest holiday. If the current week is a holiday week, HOLIDAYDISTANCE $t_{t}$ equals zero. If the current week is between two holidays, the total number of weeks between the two holidays is divided in half. As a result, HOLIDAYDISTANCE increases with the number of weeks away from the first holiday until it reaches the midpoint between the two holidays, then declines incrementally until it reaches zero again at the next holiday. To check for the robustness of this control, we also consider the number of weeks since the preceding holiday, which allows for demand seasonality to take the form of spikes followed by decay rather than smooth increases prior to, and decreases following, a major holiday. We use Memorial Day, the Fourth of July, Thanksgiving, and Christmas as the holidays in our sample, reflecting the historical importance 
of these major holidays for revenue generation for motion-pictures exhibitors and consistent with the empirical identification of major holidays in Einav (2006).

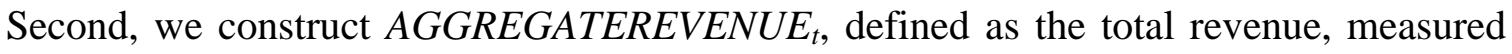
in millions of 2001 dollars, across all of the first-run theatres in our sample in week $t$, which we take as a measure of market size. ${ }^{8}$ It would be preferable, of course, to use aggregate revenue from the previous year as a measure of anticipated revenues and thus of anticipated market size. Data limitations preclude us from doing so. However, Einav's analysis, and the high correlation between HOLIDAYDISTANCE and AGGREGATEREVENUE (see Figure 1), lend support to the view that the pattern of revenues is likely to be quite stable year to year, and it is this pattern, rather than the actual levels, that we consider to be important in determining programming similarity. $^{9}$

(Figure 1 near here)

Third, we can estimate the time-variant effects by introducing weekly time dummies. If we are correct in arguing that market size effects are important, we should find a close relationship between the estimated time dummies and HOLIDAYDISTANCE or AGGREGATEREVENUE.

Finally, we address the possibility of serial correlation following Petersen (2005). We present the details of our estimation approach in Section V.

\section{Film-Programming Data and Institutional Background}

The implementation of our econometric analysis is based upon data drawn from the firstrun motion-pictures exhibition market in the Boston metropolitan area. The market contains 13

\footnotetext{
${ }^{8}$ We use aggregate revenue for the whole sample rather than by $i j$-pair to avoid endogeneity problems.

${ }^{9}$ The coefficient of correlation between HOLIDAYDISTANCE and AGGREGATEREVENUE is -0.5523.
} 
first-run theatres in and around Boston: see Figure 2 for their locations. ${ }^{10}$ For each theatre, for each week from June 30, 2000 through the week of June 22, 2001, we have information from Nielsen EDI on which films were playing, and on the revenues generated at each theatre by each film for that week. We supplemented these data by recording screening times on the Friday of each week, for each film, for each theatre in our data set. Screening-time information was determined by reviewing Boston Globe movie advertisements on microfilm. This screening information is the basis for constructing the screenings-count similarity indexes.

One first-run theatre in Quincy advertised in the Boston Globe from June 30, 2000 through September 28, 2000, but did not advertise for the remainder of the time period. We have excluded the Quincy theatre from our main empirical analysis due to these missing observations. However, when we include Quincy in our analysis and limit our period of study to June $30^{\text {th }}$ through September $28^{\text {th }}$, we obtain results qualitatively similar to our main findings, presented in Tables 2 through 4. These findings are documented in detail in Section V along with our main results.

(Figure 2 near here)

Descriptive statistics are presented in Table 1. The total number of observations for each of the similarity indexes is 4,056 , generated for $78 \mathrm{ij}$ pairs over the 52 weeks we study. As we noted above, the angular similarity index is restricted to the interval $[0,90]$ while the matching index is restricted to the interval $[0,1]$. The mean of the angular index is 39.74 and of the matching index is 0.80 . This indicates that there is some underlying degree of similarity in film programming choice across the theatre pairs in our sample. However, there is also considerable

\footnotetext{
${ }^{10}$ We exclude from our study art house and second-run theatres on the assumption that such theatres serve markets with consumer preferences for different attributes (film offerings and currency) from the first-run theatre market.
} 
variability in film programming choice, as indicated by the ranges of the angular and matching indexes. Figure 3, which illustrates the weekly pattern in the angular similarity measure for one theatre relative to the others in the sample, ${ }^{11}$ further suggests that while there are significant differences in the degree of similarity across theatre pairs, there is some consistency in the variation in the similarity measure over time, perhaps as a result of the seasonal and contractual issues noted above and identified in Einav (2006).

\section{(Table 1 near here)}

(Figure 3 near here)

DISTANCE between two ij pairs varies from a minimum of little over a mile, the distance between Copley Place and Fenway 13, both in Boston, to a maximum of roughly 54 miles, the distance between Liberty Tree Mall, Danvers and Showcase Cinemas, Randolph. The mean distance between theatre pairs is roughly 19 miles. Figure 1 suggests, and Table 1 confirms, that there is no significant difference in the average distance between theatres in our sample that are under the same ownership and those that are owned by different chains.

SAMEOWNER has a mean of 0.28 indicating that roughly twenty-eight percent of the $i j$ pairs are theatre pairs owned by the same parent company. Three companies owned the theatres comprising the first-run Boston market during our period of study: National Amusements Corporation; General Cinema (G.C.) Corporation; and Loews Cineplex Entertainment Corporation. ${ }^{12}$ Of these three companies, National Amusements held the dominant market

\footnotetext{
${ }^{11}$ The theatre we chose was Assembly Square.

12 Theatres owned by National Amusements include: Cleveland Circle Cinemas (Brookline); Quincy Cinemas; Showcase Cinemas of Dedham; Showcase Cinemas of Randolph; Showcase Cinemas of Revere; and Showcase Cinemas of Woburn. Theatres owned by General Cinema include: Braintree 10; Burlington 10; Chestnut Hill Cinema 5; and Fenway 13 (Boston). Theatres owned by Loews Cineplex Entertainment include: Assembly Square (Somerville); Copley Place (Boston); Fresh Pond 10 (Cambridge); and Liberty Tree Mall (Danvers). Note that this description includes the Quincy theatre; see discussion in note 11.
} 
position, owning six theatres, spread across the radial market around Boston, with significant coverage on or near the I-95 loop enclosing the Boston metropolitan area. General Cinema Corporation owned four theatres, distributed in a similar pattern to National Amusements' capacity, but on a smaller scale, and with proportionately greater market concentration closer to Boston. $^{13}$ Loews owned four theatres, whose locations were concentrated in the Boston/Cambridge area, with one theatre located further north on the I-95 loop. ${ }^{14}$

HOLIDAYDISTANCE has a mean of four and a maximum of ten, attained in week 11 and in weeks 36 and 37 in our sample. These are the weeks that lie midway between the Fourth of July and Thanksgiving, and between Christmas and Memorial Day, respectively.

Figure 4 compares HOLIDAYDISTANCE to the mean similarity indexes for each week for the total sample, for theatre pairs under the same ownership, and for theatre pairs under different ownership. A number of implications follow from this figure, each of which is tested formally in our econometric analysis. It does indeed seem to be the case that there is an inverse relationship between similarity in film programming choice and “distance” from major holidays (recall that the angular index is an inverse measure of similarity). Further, the dynamics of film programming choice seem quite similar whether the theatres pairs are under the same or different ownership. However, ownership appears to be important, with theatre pairs under common ownership typically exhibiting more similar film programming than those under different ownership.

\footnotetext{
${ }^{13}$ General Cinema Corporation filed for Chapter 11 reorganization on October 11, 2000; AMC Entertainment won approval to acquire General Cinema's assets in March 2002. The GCC theatres in the Boston market operated continuously throughout our period of study, and the quality and features of the theatres were similar to competing first-run theatres in the Boston market. See "Court Approves GC Cos. Sale to AMC," Boston Business Journal, March 19, 2002.
} 
(Figure 4 near here)

The demographic variables, which measure the absolute value of differences in demographic values within five-mile radii of theatre $i$ compared to the values within a five-mile radius of theatre $j$, cover age, income, population, and number of households. The AGEDIFF and INCOMEDIFF variables measure differences in average age and average income, respectively. The means of AGEDIFF, INCOMEDIFF, POPULATIONDIFF, and HOUSEHOLDDIFF are: 1.48 years; 14,127 dollars (2001 base year); 351,241; and 148,512, respectively. We focus on differences in age distribution and income in the econometric analysis.

No first-run theatres in this market opened or closed during the 52-week period of our study. Thus we can treat the spatial structure of the market as essentially constant throughout the period of study. Further, when we examine the theatre $i$ and theatre $j$ pairs using panel-data techniques, we work with a balanced data set.

\section{Econometric Model and Results}

A number of econometric considerations arise in our analysis. While our data set includes cross-sectional observations of theatre pairs over time, our main explanatory variables are time invariant: DISTANCE, SAMEOWNER, and differences in demographic characteristics. The time-varying HOLIDAYDISTANCE and AGGREGATEREVENUE serve mainly to capture seasonality (and so variation in market size) as documented in Einav (2006). More generally, in a panel-data application such as this, we must explicitly model time and theatre-pair effects, as argued in Petersen (2005).

\footnotetext{
${ }^{14}$ Loews Cineplex Entertainment Corporation resulted from the merger of Sony/Loews Theatres and Cineplex Odeon Corporation in May 1998. We treat theatres operating under either the name of Sony or Loews as being
} 
We estimate equations of the following general form, where $S I_{i j t}$ represents the similarity index of interest, either angular $\left(S A_{i j t}\right)$ or matching $\left(S M_{i j t}\right)$ :

$$
S I_{i j t}=\alpha+x_{i j t} \beta_{1}+v_{i j} \beta_{2}+\varepsilon_{i j t}
$$

Equation 4 states that the similarity index for a given theatre pair, in a given week, will be a function of time-invariant strategic factors, $v_{i j}$, within a given $i j$ theatre pair, and of time-varying factors, arising primarily from seasonality. The residual term, $\varepsilon_{i j t}$, is subject to two potential sources of non-sphericalness. First, there may be a theatre-pair-specific component of the error term. And second, the panel may be characterized by some degree of serial correlation.

To address the first point, we estimate Equation 4 with pooled OLS using Rogers (1993) standard errors, clustered by theatre-pair. Second, following Petersen (2005), when both crosssectional and time effects characterize a panel, cluster analysis by pair-specific effects should be accompanied by parametric estimation of time effects. One such approach would include dummy variables for each time period. We adopt this approach, in effect, by including the distance to the nearest holiday as a time-varying independent variable. As noted above, we repeat the estimations using AGGREGATEREVEVNUE and using weekly time dummies. The resulting estimates were effectively identical to those detailed below. We report the estimates using HOLIDAYDISTANCE since we have a clean prior expectation with respect to the impact of HOLIDAYDISTANCE on programming similarity.

To summarize, we estimate the following reduced-form equation, using pooled OLS, with Rogers standard errors, clustered by theatre pair ${ }^{15}$ :

\footnotetext{
owned by the same company.

${ }^{15}$ An alternative specification for panel data is random-effects estimation. With only one time-varying independent variable, functioning, in effect, as a time dummy, the present estimation is a better fit with the data, following Petersen (2005). Random-effects estimation yields results qualitatively similar to our main findings, presented in
} 


$$
\begin{aligned}
S_{i j t}= & \alpha+\beta_{1} \text { HOLIDAYDISTANCE }_{t}+\beta_{2} \text { SAMEOWNER }_{i j}+\beta_{3} \text { DISTANCE }_{i j}+ \\
& \beta_{4} \text { AGEDIFF }_{i j}+\varepsilon_{i j t}
\end{aligned}
$$

where the dependent variable represents either the angular measure of similarity or the normalized matching measure. Note that for the angular measures, we also include SCREENDIFF as an independent variable to control for differences in number of screens between theatres; this control is implicitly captured in the normalized similarity measure. In addition, we extend this regression by systematically replacing AGEDIFF with the three other demographic variables discussed previously.

One complication arises due to the fact that our dependent variable is truncated either on the interval $[0,90]$ or $[0,1]$. This truncation means that we might obtain predicted values outside the range of actual possible values. One way of addressing this limitation is to transform the dependent variable using, for example, a log-odds ratio. A drawback of such a transformation is that the interpretation of the estimated coefficients then becomes more complicated. Thus our preferred strategy is to report coefficients estimated using the truncated variables. ${ }^{16}$

The estimation results for the angular showtimes similarity index are presented in Table 2, Regression I. We include the demographic variable AGEDIFF in Regression I; we replace this demographic with INCOMEDIFF in Regression II.

(Table 2 near here)

\footnotetext{
Tables 2 through 4. The confidence interval on HOLIDAYDISTANCE is more narrow in the random-effects estimation, as expected in Petersen (2005).

${ }^{16}$ The matching index, $S M_{i j t}$, is the more appropriate candidate for a log-odds transformation, since it ranges from zero to one; with appropriate adjustments for values of zero and one, the problem of out-of-range predictions is addressed. The results for the $S M_{i j t}$ estimations are qualitatively similar to those presented in Section V when the estimation is repeated using a log-odds transform, $\log \left(S M_{i j t} /\left(1-S M_{i j t}\right)\right)$.
} 
The results in Table 2 indicate that theatres' offerings become more differentiated the more geographically proximate they are: a one mile reduction in distance between two theatres increases the angle between their attributes vectors by half a degree. This is consistent with our hypothesis that similarity in one characteristic, in this case location, will lead theatres to differentiate themselves in other characteristics, film programming, in order to soften competition between them. This result is robust to replacing the Euclidean distance between two theatres with travel distance. ${ }^{17}$

It is also clear that ownership affects similarity, although we noted above that the expected sign of SAMEOWNER is ambiguous. Our results show that two theatres owned by the same company are more similar in their film offerings than are two theatres owned by separate companies: changing to same ownership decreases the angle between the attributes vectors by five degrees. This suggests that the economies from studio-exhibitor contracts, and centralized control of movie program choice, are more important than coordination of programming choices to mitigate business stealing from a chain's own theatres. It should be noted, however, that this result is specific to our particular context. Sweeting's (2006) study of music variety in the radio industry finds the opposite effect: radio stations under common ownership, within the same local market, tend to be more differentiated in their music programming choices.

It might be suggested that there is some relationship between DISTANCE and SAMEOWNER. There are, however, two reasons for rejecting this. First, as we noted in the previous section, there is no significant difference in the average distance between theatres in our sample that are under the same ownership and those that are owned by different chains. Second,

17 We repeated Regression I in Table 2 including only theatre pairs with DISTANCE less than 15 miles and DISTANCE less than 20 miles. The main findings were robust to these constraints. 
when we include the interaction term DISTANCE*SAMEOWNER in our estimation, the coefficient on the interaction term is insignificant.

As expected, program selection in a particular week is more similar across theatres the nearer the week is to a major holiday, consistent with Einav's (2006) seasonality results: each additional week away from a major holiday increases the angle between attributes vectors by one degree. There is an industry pattern of wide release of holiday films, expected to appeal to a large audience, followed by more limited releases of a larger number of films expected to succeed in niche markets. The former effect leads to greater similarity in programming choice close to holidays, while the latter provides theatres more flexibility to capitalize strategically on theatre-specific strengths when market size is smaller.

When we replace HOLIDAYDISTANCE with HOLIDAYRIGHT, which measures the distance to the most-recent holiday, we still find a highly statistically significant coefficient, but the coefficient on HOLIDAYRIGHT is between one-third and one-half the size of the coefficient on HOLIDAYDISTANCE. This suggests that proximity to a holiday, on either side of the date, has more economic significance than distance from a holiday that has recently passed. It further suggests that it is the "build up" to a holiday, rather than an asymmetric decay, that is important in determining programming similarity, again consistent with patterns found in Einav (2006) for some of the major industry holidays.

This argument is further supported by the results that we obtain when we repeat the estimations using weekly time dummies. Figure 5 shows that there is a close relationship between the estimated coefficients on weekly time dummies and HOLIDAYDISTANCE.

(Figure 5 near here) 
Differences in demographic characteristics of neighboring populations also have a significant influence on the degree of differentiation in programming choice. We find a positive and significant impact of average age differences, within a five-mile radius of each theatre, on the degree of differentiation within a theatre pair. ${ }^{18}$ In other words, larger differences in the age of the surrounding population lead to more differentiated programming. The industry has long believed that the choice of which movie to see is significantly affected by the age of the moviegoer. If this is the case, then markets with very different age groups are likely to be serving consumers with different tastes, weakening the strategic interaction between these markets and leaving film programming choice to be determined more by taste than strategic considerations. ${ }^{19}$

When we replace the angular showtimes similarity index with the angular movie-count index, we obtain results that are substantively similar to the signs, magnitudes of the coefficients, and significance levels of the results in Table 2. Table 3 presents these results. ${ }^{20}$

(Table 3 near here)

The estimation results of Equation 5 using the normalized matching similarity index are presented in Table $4 .^{21}$ Note that the interpretation of the coefficients in Table 4 is the opposite of the interpretation for the angular measure: the angular measure increases with differentiation; the matching measure increases with similarity.

\footnotetext{
${ }^{18}$ The age effect is insignificant at the three-mile and ten-mile radial measures. We find that larger income differences lead to more similar programming, significant at the .10 level. The income effect is insignificant at the three-mile radial measure and significant at a ten-mile radius. When POPDIFF or HOUSEHOLDDIFF replaces the age demographic, neither is significant at three-, five-, or ten-mile radii.

${ }_{19}$ See Davis (2006) for a formal model of consumer taste parameters in the motion-pictures exhibition market.

${ }^{20}$ The demographic patterns mirror those found in Table 2; AGEDIFF is also positive and significant, at the .10 level, at a three-mile radius. The income effect is insignificant at three- and ten-mile radii. Neither the population nor the household measure is significant at three-, five-, or ten-mile radii

${ }^{21}$ The demographic patterns are as follows. AGEDIFF is no longer significant for any of the three-, five-, or tenmile radii. The income effect is positive and significant at the .10 level at the five- and ten-mile radii, but
} 
(Table 4 near here)

The results for this alternative similarity measure are qualitatively consistent with those for the angular similarity index. Similarity between theatre pairs decreases when theatres are geographically proximate, increases when theatres are under common ownership, and decreases the further the time period is from major holidays. The results are robust to replacing show counts with movie counts as the basis for constructing the similarity index. ${ }^{22}$

\section{Conclusion}

Hotelling’s claim that non-cooperative oligopolists will offer consumers product variants characterized by an "excessive sameness" has given rise to considerable debate. The result has been a large and growing theoretical literature with little consistency in its predictions and so with few clear empirically testable propositions. This is, in fact, not at all surprising. As Borenstein and Netz (1999) point out, firms competing in a simple, one-dimensional characteristics space seek to balance competing forces: an attraction force as they try to steal each others' markets and a repulsion force as they seek to soften competition. There is no reason to believe a priori that either of these forces will dominate the other.

Recent economic analysis and our reading of the marketing literature suggest that when the analysis is extended to a multi-characteristics space we have cleaner testable propositions. Simply put, we should expect to find that when firms either choose or are constrained to be more similar in some characteristics they will seek to differentiate themselves in others. In addition, we should expect to find greater similarity in larger, as opposed to smaller, markets.

insignificant at the three-mile radius. Population and household effects are insignificant at the three- and five-mile radii, and both positive and significant, at the .05 level, at the ten-mile radius. 
Our analysis has tested and provides strong support for these propositions using a dynamic data set from the U.S. motion-pictures exhibition market. In particular, our empirical results are consistent with the hypothesis that the degree of product differentiation between theatre pairs reflects a complex balance between strategic concerns and contractual considerations. Theatre pairs located more closely in geographic space make less similar programming choices. Programming similarity increases close to major holidays and declines as we move away from such holidays. These results suggest that when firms' product design choices are similar in one dimension, strengthening the business-stealing effect that underlies the attraction force, the repulsion force leads them to seek to differentiate in other dimensions. Theory is less clear regarding the impact of ownership on product differentiation. Our analysis has found evidence that theatre pairs under common ownership tend to make more similar programming choices. This may well reflect the organizational architecture in this industry, where local managers' autonomy to make programming choices is constrained by the moviestudio/theatre-chain relationship. It suggests more generally that the impact of ownership on strategic product differentiation is institution specific.

Several extensions of this work suggest themselves. Both the angular and matching indexes provide robust, dimensionless measures of the degree of differentiation between pairs of products that can be easily modified to measure product-attribute differences in a wide range of industries. This offers the potential for broader empirical investigation of the determinants of product differentiation and product similarity. Looking specifically at the movie exhibition market, the basic unit of analysis in this paper has been the degree of similarity between theatre

\footnotetext{
${ }^{22}$ The signs of the coefficients remain the same as in Table 4. All of the variables that are statistically significant in Table 4 maintain their statistically significant levels, with the exceptions of SAMEOWN moving to a .10 significance
} 
pairs. Similarity, in turn, is determined by specific decision-making at the individual theatre level, regarding which films should be retained and which should be dropped from week to week. In our future work we hope to apply models of duration analysis to these more microlevel decisions. ${ }^{23}$

level, and INCDIFF, falling just below the .10 level, with a p-value of 0.129.

${ }^{23}$ Some preliminary results are presented in Chisholm and Norman (2006b). 
Table 1. Descriptive Statistics for First-Run Theatres in Boston Metropolitan Market June 30, 2000-Jun 22, 2001

\begin{tabular}{|c|c|c|c|c|c|c|c|c|c|c|c|c|}
\hline \multirow[b]{2}{*}{ Variable } & \multirow[b]{2}{*}{ Mean } & \multicolumn{3}{|c|}{ All Theatre Pairs } & \multicolumn{4}{|c|}{$\begin{array}{c}\text { Theatre Pairs with Same } \\
\text { Owners Only }\end{array}$} & \multicolumn{4}{|c|}{$\begin{array}{c}\text { Theatre Pairs with Different } \\
\text { Owners Only }\end{array}$} \\
\hline & & St. Dev. & Min. & Max. & Mean & St. Dev. & Min. & Max. & Mean & St. Dev. & Min. & Max. \\
\hline $\begin{array}{l}\text { Angular Similarity Index, } \\
\mathrm{SA}_{\mathrm{t}}\end{array}$ & 39.74 & 16.33 & 4.40 & 90.00 & 36.28 & 15.30 & 4.40 & 90.00 & 41.09 & 16.53 & 7.63 & 90.00 \\
\hline $\begin{array}{l}\text { Normalized Matching } \\
\text { Similarity Index, } \mathrm{SM}_{\mathrm{t}}\end{array}$ & 80.41 & 18.99 & 0.00 & 100.00 & 85.29 & 16.07 & 0.00 & 100.00 & 78.49 & 19.70 & 0.00 & 100.00 \\
\hline SAME OWNER & 0.28 & 0.45 & 0.00 & 1.00 & 1.00 & 0.00 & 1.00 & 1.00 & 0.00 & 0.00 & 0.00 & 0.00 \\
\hline DISTANCE & 18.74 & 11.63 & 1.24 & 54.04 & 19.99 & 11.04 & 2.58 & 44.93 & 18.25 & 11.82 & 1.24 & 54.04 \\
\hline SCREEN DIFF & 5.08 & 3.65 & 0.00 & 15.00 & 5.23 & 3.34 & 0.00 & 13.00 & 5.08 & 3.77 & 0.00 & 15.00 \\
\hline HOLIDAYDISTANCE $_{t}$ & 4.33 & 3.09 & 0.00 & 10.00 & 4.33 & 3.09 & 0.00 & 10.00 & 4.33 & 3.09 & 0.00 & 10.00 \\
\hline AGEDIFF & 1.48 & 0.97 & 0.03 & 3.56 & 1.63 & 0.94 & 0.03 & 3.22 & 1.42 & 0.98 & 0.08 & 3.56 \\
\hline INCOMEDIFF & 14.13 & 11.38 & 0.02 & 46.42 & 14.31 & 11.69 & 0.10 & 37.66 & 14.05 & 11.25 & 0.02 & 46.42 \\
\hline POPULATIONDIFF & 35.12 & 24.36 & 0.46 & 74.15 & 35.57 & 23.47 & 0.46 & 72.12 & 34.95 & 24.71 & 1.92 & 74.15 \\
\hline HOUSEHOLDDIFF & 14.85 & 10.36 & 0.34 & 31.39 & 14.83 & 9.84 & 0.15 & 29.98 & 14.86 & 10.56 & 0.34 & 31.39 \\
\hline
\end{tabular}

\footnotetext{
Similarity indexes are based on showtime counts.
}

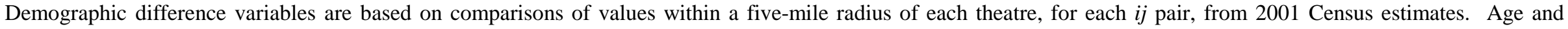

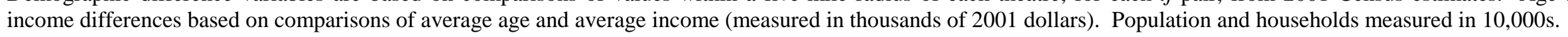

Total number of observations is 4,056. Total number of observations with same owner is 1,144; total number of observations with different owners is 2,912 . 
Table 2. Estimation of Angular Show-Count Similarity Index

\begin{tabular}{lcc}
\hline \hline Variable & $(\mathrm{I})$ & $(\mathrm{II})$ \\
\hline CONSTANT & 34.59 & 41.16 \\
& $(7.33)^{* * *}$ & $(9.62)^{* * *}$ \\
SAMEOWNER & -4.94 & -4.27 \\
& $(-1.77)^{*}$ & $(-1.42)$ \\
DISTANCE & -0.47 & -0.44 \\
& $(-4.25)^{* * *}$ & $(-4.01)^{* * *}$ \\
HOLIDAYDISTANCE & 1.01 & 1.01 \\
& $(16.11)^{* * *}$ & $(16.11)^{* * *}$ \\
SCREENDIFF & 1.26 & 1.26 \\
& $(3.62)^{* * *}$ & $(3.40)^{* * *}$ \\
AGEDIFF & 3.15 & \\
& $(2.42)^{* * *}$ & \\
INCOMEDIFF & & -0.20 \\
& & $(-1.82)^{*}$ \\
Sample Size & & \\
$\mathrm{R}^{2}$ & 4056 & 4056 \\
F value & 0.2428 & 76.14 \\
\hline
\end{tabular}

Estimation by pooled OLS with Rogers standard errors, clustered by theatre pair.

Dependent variable is $\mathrm{SA}_{t}$, the angle between theatre-pair attributes vectors, using showtime counts.

Age and income differences are based on comparisons of average age and average income, in thousands of 2001 dollars, within a five-mile radius of each theatre, for each $i j$ theatre pair, from 2001 Census estimates.

Significance levels *.10, **.05, ***.01; t-values reported in parentheses. 
Table 3. Estimation of Angular Movie-Count Similarity Index

\begin{tabular}{lcc}
\hline \hline Variable & (I) & $(\mathrm{II})$ \\
CONSTANT & 37.82 & 43.65 \\
& $(8.74)^{* * *}$ & $(11.08)^{* * *}$ \\
SAMEOWNER & -3.92 & -3.32 \\
& $(-1.64)$ & $(-1.25)$ \\
DISTANCE & -0.45 & -0.41 \\
& $(-4.51)^{* * *}$ & $(-4.26)^{* * *}$ \\
HOLIDAYDISTANCE & & 0.88 \\
& 0.88 & $(14.29)^{* * *}$ \\
SCREENDIFF & $(14.29)^{* * *}$ & 1.29 \\
& 1.29 & $(4.59)^{* * *}$ \\
AGEDIFF & $(4.96)^{* * *}$ & \\
& 2.87 & \\
INCOMEDIFF & $(2.52)^{* *}$ & -0.167 \\
& & $(-1.74)^{*}$ \\
Sample Size & & \\
$\mathrm{R}^{2}$ & & 4056 \\
F-value & 4056 & 0.2399 \\
\hline S & 0.2581 &
\end{tabular}

Estimation by pooled OLS with Rogers standard errors, clustered by theatre pair.

Dependent variable is $\mathrm{SA}_{t}$, the angle between theatre-pair attributes vectors, using movie counts.

Age and income differences are based on comparisons of average age and average income, in thousands of 2001 dollars, within a five-mile radius of each theatre, for each $i j$ theatre pair, from 2001 Census estimates.

Significance levels *.10, ${ }^{* *} .05,{ }^{* * *} .01$; t-values reported in parentheses. 
Table 4. Estimation of Normalized Matching Show-Count Similarity Index

\begin{tabular}{lcc}
\hline Variable & (I) & (II) \\
CONSTANT & 74.10 & 69.11 \\
& $(12.77)^{* * *}$ & $(13.21)^{* * *}$ \\
SAMEOWNER & 6.26 & 5.88 \\
& $(2.14)^{* *}$ & $(1.87)^{*}$ \\
DISTANCE & 0.53 & 0.50 \\
& $(3.61)^{* * *}$ & $(3.54)^{* * *}$ \\
HOLIDAYDISTANCE & & -0.65 \\
& -0.65 & $(-11.33)^{* * *}$ \\
AGEDIFF & $(-11.33)^{* * *}$ & \\
& -1.71 & \\
INCOMEDIFF & $(-1.08)$ & 0.22 \\
& & $(1.69)^{*}$ \\
Sample Size & & \\
$\mathrm{R}^{2}$ & & 4056 \\
F value & 4056 & 0.1523 \\
\hline
\end{tabular}

Dependent variable is $\mathrm{SM}_{\mathrm{t}}$, the normalized matching index, using showtime counts.

Age and income differences are based on comparisons of average age and average income, measured in thousands of 2001 dollars, within a five-mile radius of each theatre, for each $i j$ theatre pair, from 2001 Census estimates.

Significance levels *.10, ${ }^{* *} .05,{ }^{* * *} .01$; t-values reported in parentheses. 


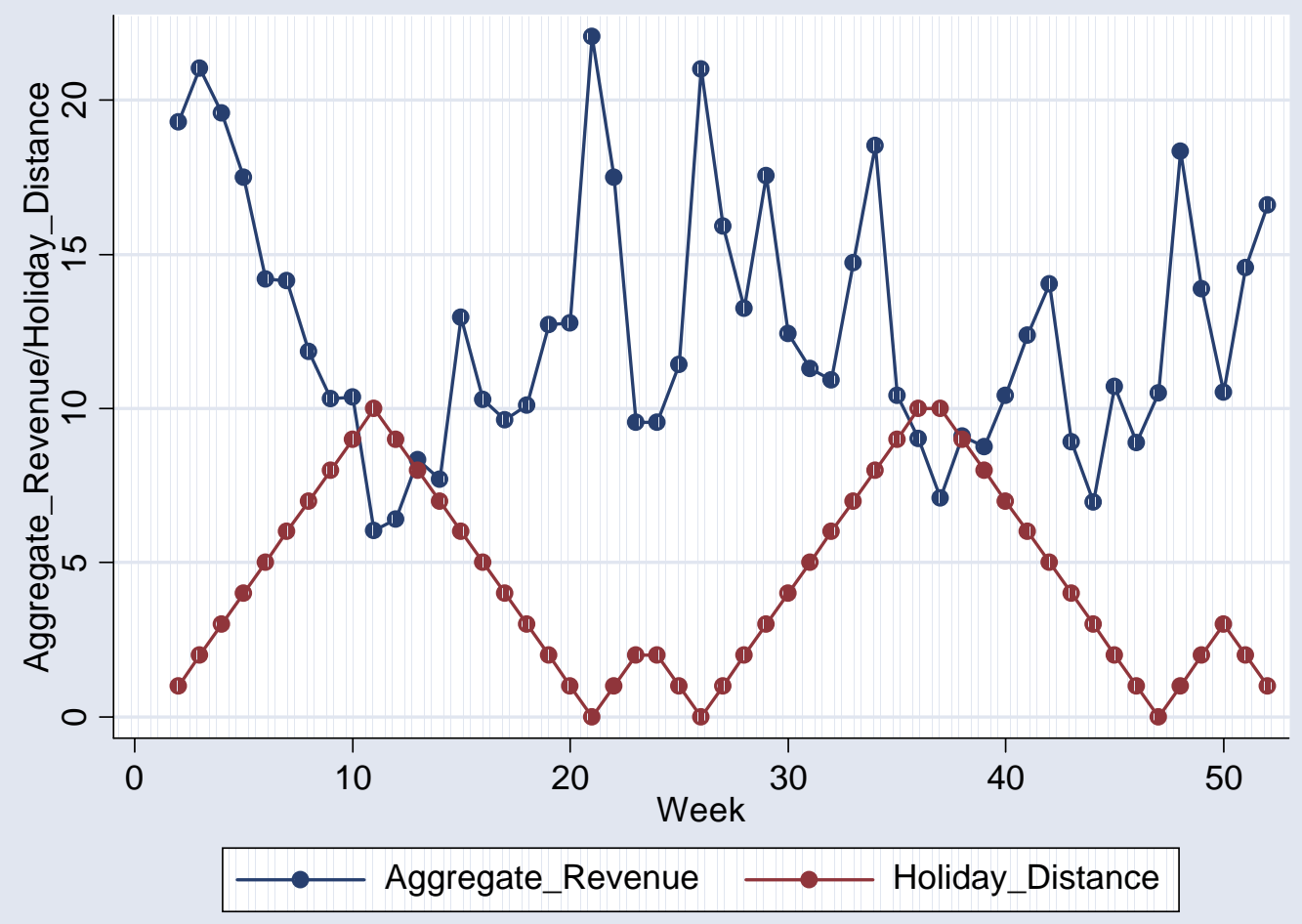

Figure 1: Aggregate Revenue $\mathbf{( \$ 1 0 0 , 0 0 0 s )}$ and Holiday Distance

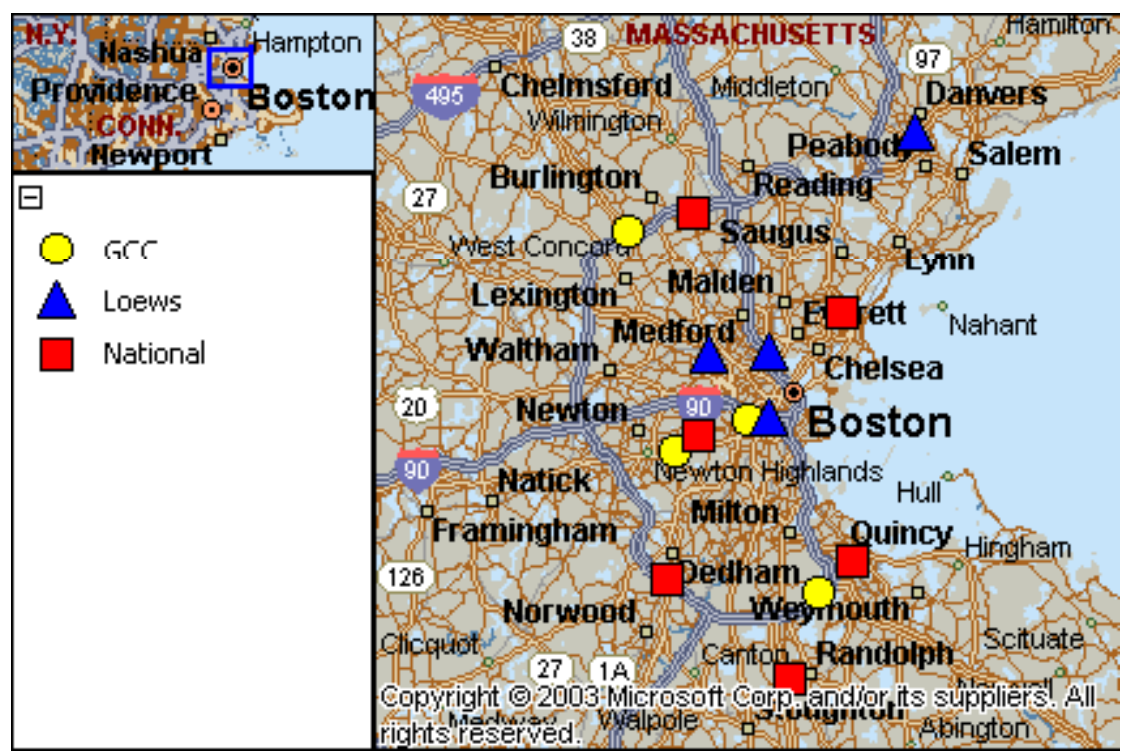

Figure 2: Theatre Locations by Owner Boston MSA 2000. 


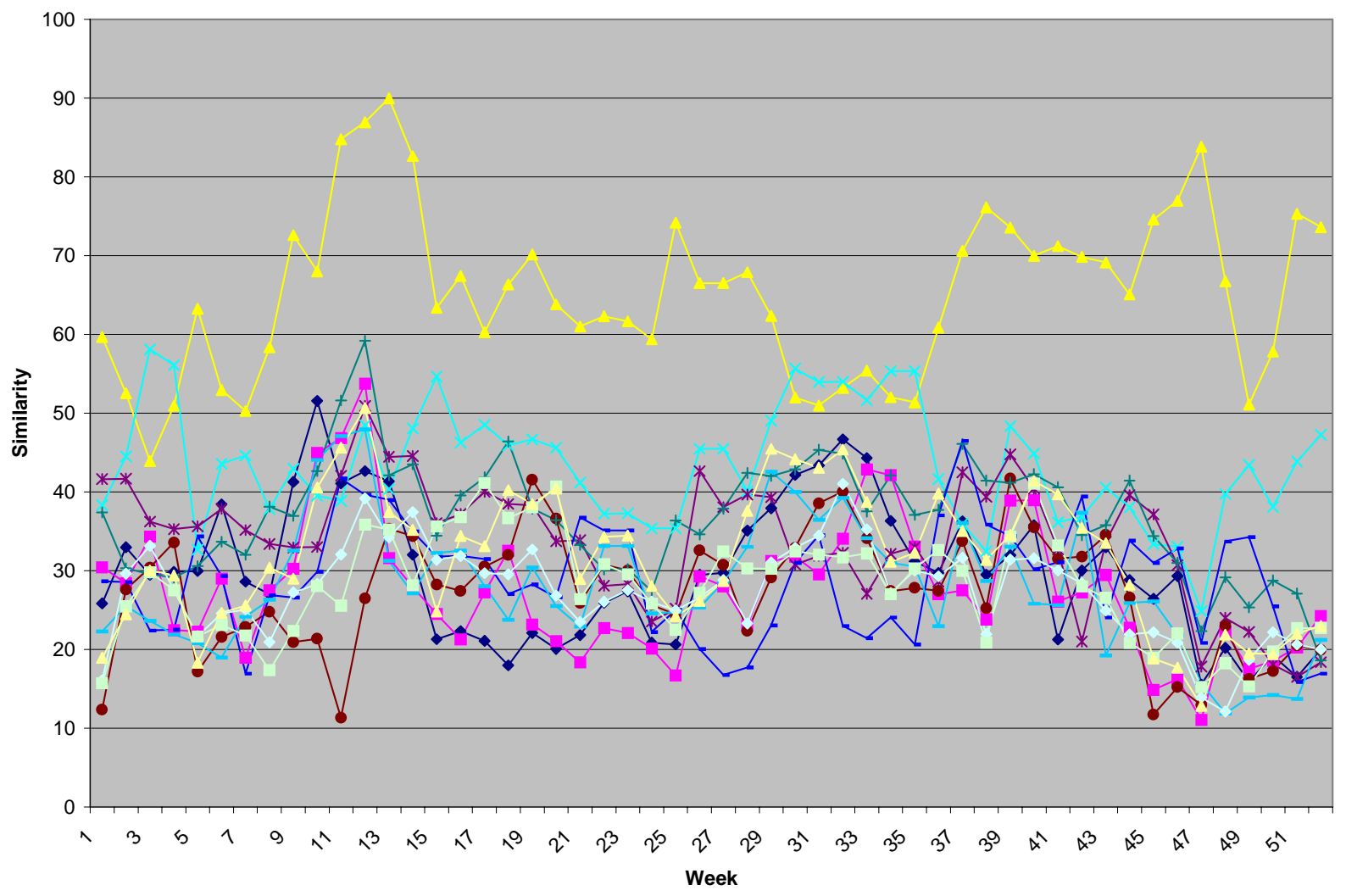

Figure 3: Angular Similarity Measure for Assembly Theatre 
Mean Normalized Matching Similarity Index

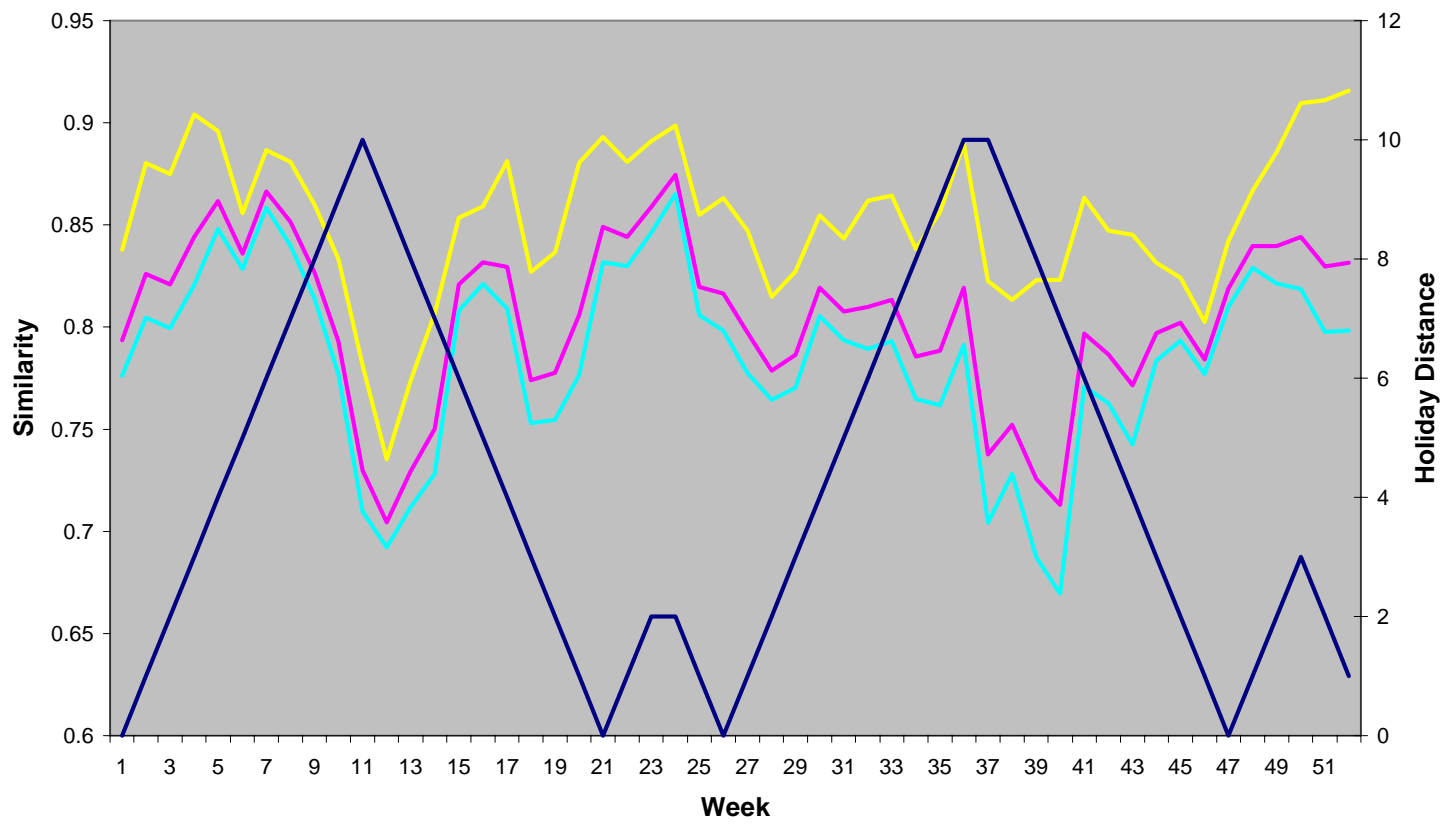

-All Observations — Same Owner Only —-Different Owner Only — Holiday Distance

Mean Angular Similarity Index

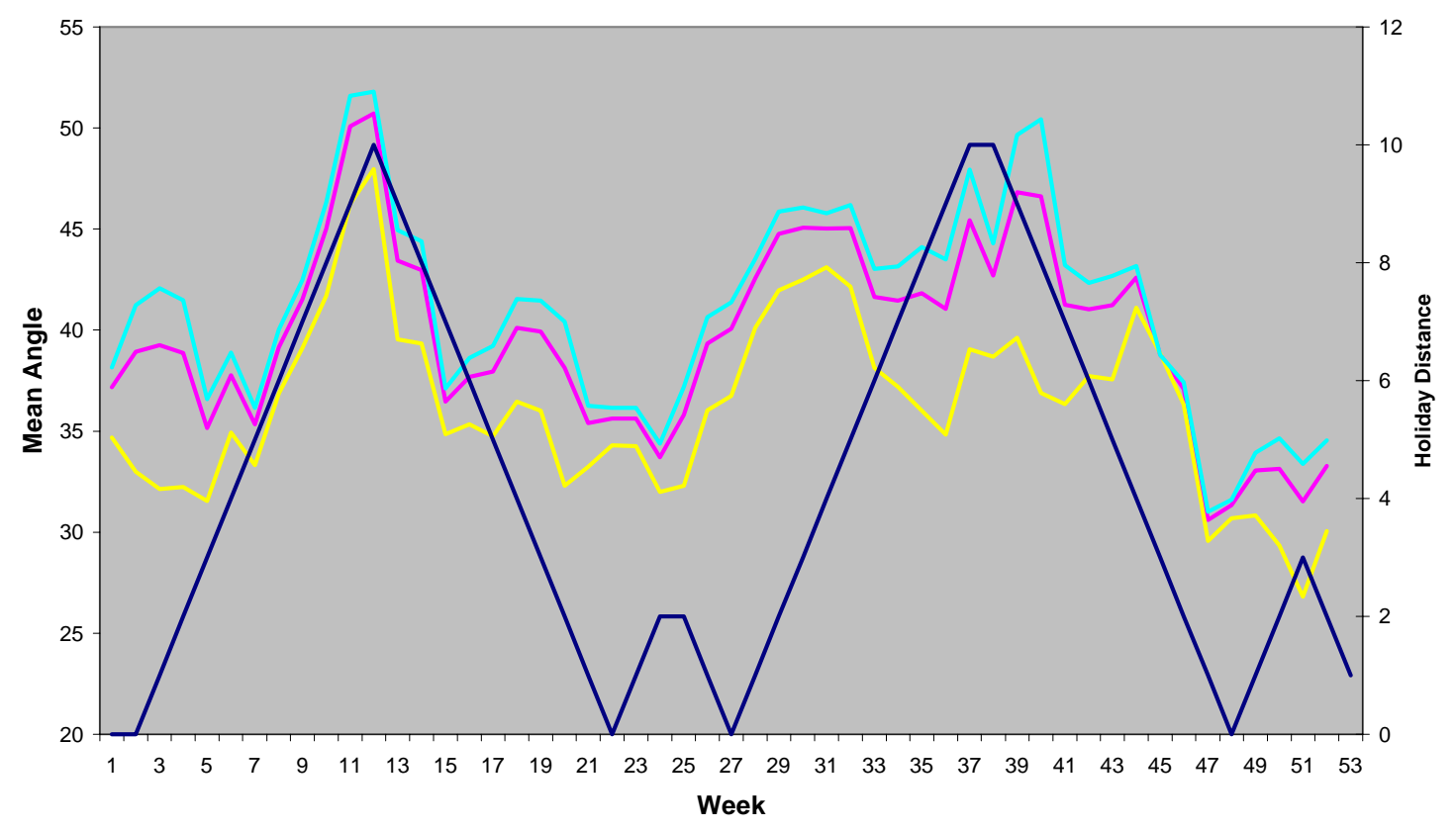

-All Observations — Same Owner Only —Different Owner Only — Holiday Distance

Figure 4: Holiday Distance and Mean Similarity Indexes by Week 


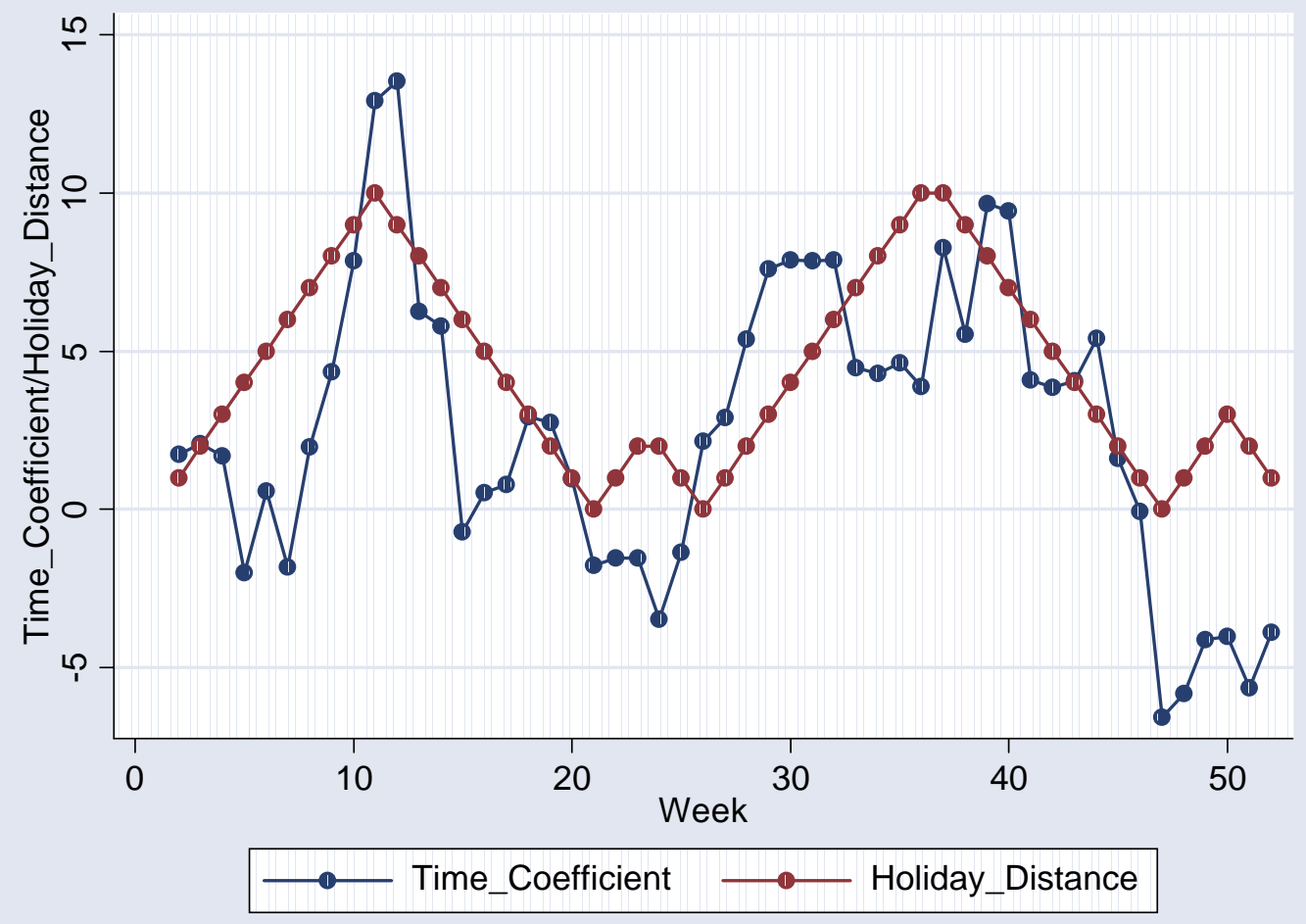

Figure 5: Estimated Weekly Time Coefficients from Table 2 (I) and Holiday Distance 


\section{References}

Berry, Steven T. and Waldfogel, Joel. 2001. "Do Mergers Increase Product Variety? Evidence from Radio Broadcasting,” Quarterly Journal of Economics, Volume 116, pp. 10091025.

Borenstein, Severin and Netz, Janet. 1999. "Why Do All the Flights Leave at 8 AM? Competition and Departure-Time Differentiation in Airline Markets," International Journal of Industrial Organization, Volume 17, pp. 611-40.

Chisholm, Darlene C. and Norman, George. 2004. "Heterogeneous Preferences and Location Choice with Multi-Product Firms,” Regional Science and Urban Economics, Volume 34, pp. 321-339.

Chisholm, Darlene C. and Norman, George. 2006a. "Market Size and Overlapping Characteristics in Multi-Product Firm Rivalry,” Tufts University mimeo.

Chisholm, Darlene C. and Norman, George. 2006b. "When to Exit a Product: Evidence from the U.S. Motion-Picture Exhibition Market," American Economic Review, Papers and Proceedings, Volume 96, pp. 57-61.

Corts, Kenneth S. 2001. “The Strategic Effects of Vertical Market Structure: Common Agency and Divisionalization in the US Motion Picture Industry," Journal of Economics and Management Strategy, Volume 10, pp. 509-528.

d'Aspremont, Claude, Gabszewicz, Jean J. and Thisse, Jacques-Francois. 1979. “On Hotelling's 'Stability in Competition,”' Econometrica, Volume 47, pp. 1145-50.

Davis, Peter. 2006. "Spatial Competition in Retail Markets: Movie Theaters." RAND Journal of Economics, forthcoming.

Einav, Liran. 2003. "Not All Rivals Look Alike: Estimating an Equilibrium Model of the Release Date Timing Game,” Stanford University mimeo.

Einav, Liran. 2006. "Seasonality in the U.S. Motion Picture Industry," RAND Journal of Economics, forthcoming.

Hotelling, Harold. 1929. “Stability in Competition,” Economic Journal, Volume 39, pp. 41-57.

Irmen, Andreas and Thisse, Jacques-Francois. 1998. "Competition in Multi-Characteristics Spaces: Hotelling Was Almost Right,” Journal of Economic Theory, Volume 78, pp. 76102. 
Jaffe, Adam B. 1986. "Technological Opportunity and Spillovers of R\&D: Evidence from Firms’ Patents, Profits, and Market Value,” American Economic Review, Volume 76, pp. 984-1001.

Kerin, Roger A., Hartley, Steven W., Berkowitz, Eric N., and Rudelius, William. 2006. Marketing ( $8^{\text {th }}$ edition), McGraw-Hill, New York, New York.

Mazzeo, Michael J. 2002a. "Product Choice and Oligopoly Market Structure," RAND Journal of Economics, Volume 33, pp. 221-242.

Mazzeo, Michael J. 2002b. "Competitive Outcomes in Product-Differentiated Oligopoly," Review of Economics and Statistics, Volume 84, pp. 716-728.

Netz, Janet S. and Taylor, Beck A. 2002. "Maximum or Minimum Differentiation? Location Patterns of Retail Outlets,” Review of Economics and Statistics, Volume 84, pp. 162-75.

Norman, George and Pepall, Lynne. 2000. "Profitable Mergers in a Cournot Model of Spatial Competition,” Southern Economic Journal, Volume 66, pp. 667-681.

Pal, Debashis and Sarkar, Jyotirmoy. 2002. "Spatial Competition Among Multi-Plant Firms," International Journal of Industrial Organization, Volume 20, pp. 163-190.

Petersen, Mitchell A. 2005. "Estimating Standard Errors in Finance Panel Data Sets: Comparing Approaches,” National Bureau of Economic Research Working Paper 11280.

Rogers, W.H. 1993. "Regression Standard Errors in Clustered Samples: sg17.” Stata Technical Bulletin, Volume 13, pp. 19-23, reprinted in Stata Technical Bulletin Reprints, Volume 3, pp. 88-94.

Seim, Katja. 2005. "An Empirical Model of Firm Entry with Endogenous Product Type Choices," RAND Journal of Economics, forthcoming.

Sweeting, Andrew. 2006. "Too Much Rock and Roll? Station Ownership, Programming and Listenership in the Music Radio Industry,” Northwestern University Working Paper.

Tirole, Jean. 1988. The Theory of Industrial Organization, The MIT Press, Cambridge, Massachusetts. 